\title{
ON CONNECTEDNESS IN INTUITIONISTIC FUZZY SPECIAL TOPOLOGICAL SPACES
}

\author{
SELMA ÖZÇAĞ \\ Department of Mathematics \\ Hacettepe University, \\ Beytepe \\ 06532-Ankara / TURKEY \\ DOĞAN ÇOKER \\ Department of Mathematics Education \\ Hacettepe University, \\ Beytepe \\ 06532-Ankara / TURKEY
}

(Received May 1, 1996 and in revised form July 7, 1996)

\begin{abstract}
The aim of this paper is to construct the basic concepts related to connectedness in intuitionistic fuzzy special topological spaces. Here we introduce the concepts of $\mathrm{C}_{5}$-connectedness, connectedness, $\mathrm{C}_{S}$-connectedness, $\mathrm{C}_{\mathbf{M}}$-connectedness, strong connectedness, super connectedness, $\mathrm{C}_{\mathrm{j}}$ connectedness $(i=1,2,3,4)$, and, obtain several preservation properties and some characterizations concerning connectedness in these spaces.
\end{abstract}

KEY WORDS AND PHRASES. Intuitionistic fuzzy special set; intuitionistic fuzzy special topology, intuitionistic fuzzy special topological space, continuity; C5-connectedness; connectedness; CS-

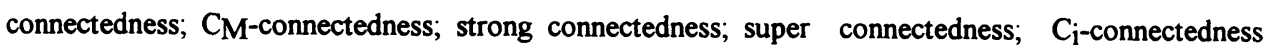
$(\mathrm{i}=1,2,3,4)$.

1992 AMS SUBJECT CLASSIFICATION CODE. 04A99.

\section{INTRODUCTION}

After the introduction of the concept of fuzzy sets by Zadeh [1] several researches were conducted on the generalizations of the notion of fuzzy set. The idea of intuitionistic fuzzy set was first published by Krassimir Atanassov [2] and many works by the same author appeared in the literature (see Atanassov [2,3]) Later this concept is used to define intuitionistic fuzzy special sets by Coker [4] and intuitionistic fuzzy topological spaces are introduced by Çoker [5], Coker-Es [6].In this direction some preliminary concepts are also defined by Copkun-Çoker[7].Here we shall give the classical version of this kind of fuzzy topological space in the framework of connectedness; 
especially, we shall make use of several types of fuzzy connectedness in intuitionistic fuzzy topological spaces in Turanli-Coker [8].

\section{PRELIMINARIES}

First we shall present the fundamental definitions. The following one is obviously inspired by $\mathrm{K}$. Atanassov [2,3]:

DEFINITION 2.1. (see Çoker [4] Let $X$ be a nonempty fixed set. An intuitionistic fuzzy special set (IFSS for short) $A$ is an object having the form $A=\left\langle x, A_{1}, A_{2}>\right.$, where $A_{1}$ and $A_{2}$ are subsets of $X$ satisfying $A_{1} \cap A_{2}=\varnothing$. The set $A_{1}$ is called the set of members of $A$, while $A_{2}$ is called the set of nonmembers of $A$.

Obviously every set $\mathrm{A}$ on a nonempty set $\mathrm{X}$ is obviously an IFSS having the form $<x, A, A>$ One can define several relations and operations between IFSS's as follows.

DEFINITION 2.2. (see Çoker [4,5]) Let $X$ be a nonempty set, and the IFSS's $A$ and $B$ be in the form $A=<x, A_{1}, A_{2}>, B=<x, B_{1}, B_{2}>$, respectively. Furthermore, let $\left\{A_{i} \cdot i \in J\right\}$ be an arbitrary family of IFSS's in $X$, where $A=<x, A_{1}^{(1)}, A_{1}^{(2)}>$. Then
(a) $A \subseteq B$ iff $A_{1} \subseteq B_{1}$ and $A_{2} \supseteq B_{2}$;
(b) $A=B$ iff $A \subseteq B$ and $B \subseteq A$;
(c) $\bar{A}=<x, A_{2}, A_{1}>$;
(d) [] $A=<x, A_{1}, A_{1}^{c}>$,
(e) $>A=<x, A_{2}^{c}, A_{2}>$,
(f) $\cup A \mathrm{i}=<x, \cup A_{1}^{(1)} \cap A_{1}^{(2)}>$,
(g) $\left.\cap A i=<x, \cap A_{1}^{(1)}, \cup A_{1}^{(2)}\right\rangle$;
(h) $\underset{\sim}{\varnothing}=<\mathrm{x}, \varnothing, \mathrm{X}>$ and $\underset{\sim}{\mathrm{X}}=<\mathrm{x}, \mathrm{X}, \varnothing>$.

We shall define the image and preimage of IFSS's. Let $\mathrm{X}$ and $\mathrm{Y}$ be two nonempty sets and $\mathrm{f} \cdot \mathrm{X} \rightarrow \mathrm{Y}$ a function.

DEFINITION 2.3. (see Çoker $[4,5]$ ) (a) If $B=<y, B_{1}, B_{2}>$ is an IFSS in $Y$, then the preimage of $B$ under $f$, denoted by $f^{-1}(B)$, is the IFSS in $X$ defined by $f^{-1}(B)=\left\langle x, f^{-1}\left(B_{1}\right), f^{-1}\left(B_{2}\right)>\right.$

(b) If $A=<x, A_{1}, A_{2}>$ is an IS in $X$, then the image of $A$ under $f$, denoted by $f(A)$, is the IFSS in $Y$ defined by $f(A)=\left\langle y, f\left(A_{1}\right), f \_\left(A_{2}\right)>\right.$, where $f_{-}\left(A_{2}\right)=\left(f\left(A_{2}^{c}\right)\right)^{c}$

COROLLARY 2.1. Let $A, A_{1}(i \in J)$ be IFSS's in $X, B, B_{j}(j \in K)$ IFSS's in $Y$ and $f: X \rightarrow Y$ a function. Then
(a) $A_{1} \subseteq A_{2} \Rightarrow f\left(A_{1}\right) \subseteq f\left(A_{2}\right)$
(b) $B_{1} \subseteq B_{2} \Rightarrow f^{-1}\left(B_{1}\right) \subseteq f^{-1}\left(B_{2}\right)$
(c) $A \subseteq f^{-1}(f(A))$ and if $f$ is injective, then $A=f^{-1}(f(A))$.
(d) $f\left(f^{-1}(B)\right) \subseteq B$, and if $f$ is surjective, then $f\left(f^{-1}(B)\right)=B$
(e) $f^{-1}\left(\cup B_{j}\right)=\cup f^{-1}\left(B_{j}\right)$
(f) $f^{-1}\left(\cap B_{J}\right)=\cap f^{-1}\left(B_{J}\right)$
(g) $f\left(\cup A_{i}\right)=\cup f\left(A_{1}\right)$
(h) $f\left(\cap A_{1}\right) \subseteq \cap f\left(A_{1}\right)$, and if $f$ is injective, then $f\left(\cap A_{1}\right)=\cap f\left(A_{1}\right)$
(i) $\mathrm{f}^{-1}(\underset{\sim}{\mathrm{Y}})=\underset{\sim}{\mathrm{X}}$
(j) $\mathrm{f}^{-1}(\underset{\sim}{\varnothing})=\varnothing$
(k) $f(\underset{\sim}{X})=\underset{\sim}{Y}$ if $f$ is surjective.
(l) $\mathrm{f}(\underset{\sim}{\varnothing})=\varnothing$
(m) If $f$ is surjective, then $\overline{f(A)} \subseteq f(\bar{A})$; and if, furthermore, $f$ is injective, we have $\overline{(f(A))}-f(\bar{A})$.
(n) $\mathrm{f}^{-1}(\overline{\mathrm{B}})=\overline{\mathrm{f}^{-1}(\mathrm{~B})}$ 
DEFINITION 2.4 (see Coker [5,9], Coker-Es [6]) An intuitionistic fuzzy special topology (IFST for short) on a nonempty set $\mathrm{X}$ is a family $\tau$ of IFSS's in X containing $\underset{\sim}{\varnothing}, \underset{\sim}{\mathrm{X}}$, and closed under finite infima and arbitrary suprema. In this case the pair $(X, \tau)$ is called an intuitionistic fuzzy special topological space (IFSTS for short) and any IFSS in $\tau$ is known as an intuitionistic fuzzy special open set (IFSOS for short) in X.

Any topological space can be obviously treated as an IFSTS in a usual manner.

PROPOSITION 2.1. Let $(X, \tau)$ be an IFSTS on $X$. Then, we can also construct several IFSTS's on $\mathrm{X}$ in the following way.
(a) $\tau_{0,1}=\{[] G: G \in \tau\}$,
(b) $\tau_{0,2}=\{\diamond \mathrm{G}: \mathrm{G} \in \tau\}$.

REMARK 2.1 Let $(X, \tau)$ be an IFSTS $\tau_{1}=\left\{G_{1} G=<x, G_{1}, G_{2}>\in \tau\right\}$ is a topological space on $X$ $\tau_{2}^{*}=\left\{G_{2}: G=<x, G_{1}, G_{2}>\in \tau\right\}$ is the family of all closed sets of the topological space $\left(\tau_{2}=\left\{G_{2}^{c}\right.\right.$ $\left.\mathrm{G}=<\mathrm{x}, \mathrm{G}_{1}, \mathrm{G}_{2}>\in \tau\right\}$ on $\mathrm{X}$.

The complement $\bar{A}$ of an IFSOS $\mathrm{A}$ in an IFSTS $(\mathrm{X}, \tau)$ is called an intuitionistic fuzzy special closed set (IFSCS for short) in X, and the interior and closure of an IFSS $\mathrm{A}$ are defined by

$$
\operatorname{cl}(A)=\cap\{K: K \text { is an IFSCS in } X \text { and } A \subseteq K\} \text {, }
$$$$
\operatorname{int}(A)=\cup\{G: G \text { is an IFSOS in } X \text { and } G \subseteq A\}
$$

DEFINITION 2.5. Let $(X, \tau)$ be an IFSTS on $X$. If $A=\operatorname{int}(\operatorname{cl}(A))$, then $A$ is called an intuitionistic fuzzy special regular open set in $X$

DEFINITION 2.6. Let $(X, \tau)$ and $(Y, \psi)$ be two IFSTS's and let $f: X \rightarrow Y$ be a function. Then $f$ is said to be continuous iff the preimage of each IFSS in $\psi$ is an IFSS in $\tau$

Here we obtain some characterizations of continuity.

PROPOSITION 2.2 The following are equivalent to each other:

(a) $f$. $(X, \tau) \rightarrow(Y, \psi)$ is continuous.

(b) The preimage of each IFSCS in Y is an IFSCS in X

(c) $\mathrm{f}^{-1}(\operatorname{int}(B)) \subseteq \operatorname{int}\left(\mathrm{f}^{-1}(B)\right)$ for each IFSS B in $\mathrm{Y}$.

(d) $\mathrm{cl}\left(\mathrm{f}^{-1}(\mathrm{~B})\right) \subseteq\left(\mathrm{f}^{-1}(\mathrm{cl}(\mathrm{B}))\right.$ for each IFSS $\mathrm{B}$ in $\mathrm{Y}$

\section{TYPES OF CONNECTEDNESS IN INTUITIONISTIC FUZZY SPECIAL}

\section{TOPOLOGICAL SPACES}

Throughout this section $(\mathrm{X}, \tau)$ and $(\mathrm{Y}, \psi)$ will always denote IFSTS's We shall define several types of connectedness in IFSTS's

DEFINITION 3.1. (see Chaudhuri-Das [10], Turanli-Coker [8])

(a) $\mathrm{X}$ is called $\mathrm{C}_{5}$-disconnected, if there exists an IFSS $\mathrm{A}$ which is both intuitionistic fuzzy special open and intuitionistic fuzzy special closed, such that $\underset{\sim}{\varnothing} \mathrm{A} \neq \underset{\sim}{\mathrm{X}}$.

(b) $\mathrm{X}$ is called $\mathrm{C}_{5}$-connected, if $\mathrm{X}$ is not $\mathrm{C}_{5}$-disconnected.

(c) $\mathrm{X}$ is called disconnected, if there exist IFSOS's $\mathrm{A} \neq \underset{\sim}{\varnothing}$ and $\mathrm{B} \neq \underset{\sim}{\varnothing}$ such that $\mathrm{A} \cup \mathrm{B}=\underset{\sim}{\mathrm{X}}$ and $\mathrm{A} \cap \mathrm{B}=\varnothing$ 
(d) $\mathrm{X}$ is called connected, if $\mathrm{X}$ is not disconnected.

PROPOSITION 3.1. $C_{5}$-connectedness implies connectedness.

PROOF. Suppose that there exist nonempty IFSOS's $A$ and $B$ such that $A \cup B=\underset{\sim}{X}, A \cap B=\underset{\sim}{\varnothing}$, from which we get $A_{1} \cup B_{1}=X, A_{2} \cap B_{2}=\varnothing, A_{1} \cap B_{1}=\varnothing, A_{2} \cup B_{2}=X$, in other words, $A=\bar{B}$. Hence $A$ is intuitionistic fuzzy special clopen, i.e. $(X, \tau)$ is $C_{5}$-disconnected.

COUNTEREXAMPLE 3.1. Consider the IFTS $\tau$ on $X=\{a, b, c, d\}$, where $\tau=\left\{\underset{\sim}{\varnothing} \underset{\sim}{X}, A_{1}, A_{2}, A_{3}, A_{4}\right\}$, $A_{1}=<x,\{a\},\{b, c\}>, A_{2}=<x,\{b, c\},\{a\}>, A_{3}=<x, \varnothing,\{a, b, c\}>, A_{4}=<x,\{a, b, c\}, \varnothing>(X, \tau)$ is connected, but not $C_{5}$-connected (namely, $A_{4}$ is intuitionistic fuzzy special clopen in $X$ ).

PROPOSITION 3.2. Let $\mathrm{f}:(\mathrm{X}, \tau) \rightarrow(\mathrm{Y}, \Psi)$ be a continuous surjection. If $\mathrm{X}$ is connected, then so is $\mathrm{Y}$.

PROOF. Assume that $\mathrm{Y}$ is disconnected Thus there exist IFSOS's $\mathrm{C} \neq \underset{\sim}{\varnothing}, \mathrm{D} \neq \underset{\sim}{\varnothing}$ in $\mathrm{Y}$ such that $\mathrm{C} \cup \mathrm{D}=\underset{\sim}{\mathrm{Y}}, \mathrm{C} \cap \mathrm{D}=\underset{\sim}{\varnothing}$. Now we see that $\mathrm{A}=\mathrm{f}^{-1}(\mathrm{C}), \mathrm{B}=\mathrm{f}^{-1}(\mathrm{D})$ are IFSOS's in $\mathrm{X}$, since $\mathrm{f}$ is continuous From $C \neq \underset{\sim}{\varnothing}$, we get $A=f^{-1}(C) \neq \varnothing_{\sim} \quad$ (If $f^{1}(C)=\underset{\sim}{\varnothing}$, then $C=f^{-1}(C)=f(\underset{\sim}{\varnothing})=\underset{\sim}{\varnothing}$, which is a contradiction.) Similarly, we obtain $B \neq \underset{\sim}{\varnothing}$. Now $C \cup D=\underset{\sim}{Y} \Rightarrow f^{-1}(C) \cup f^{-1}(D)=f^{1}(\underset{\sim}{Y})=\underset{\sim}{X} \Rightarrow A \cup B=\underset{\sim}{X}$, $\mathrm{C} \cap \mathrm{D}=\varnothing_{\sim}^{\varnothing} \Rightarrow \mathrm{f}^{1}(\mathrm{C}) \cap \mathrm{f}^{-1}(\mathrm{D})=\mathrm{f}^{1}\left(\bigodot_{\sim}\right)=\varnothing_{\sim} \Rightarrow \mathrm{A} \cap \mathrm{B}=\varnothing_{\sim}$. But this is a contradiction to our hypothesis, thus $\mathrm{Y}$ is connected.

PROPOSITION 3.3. If $(X, \tau)$ is disconnected, then so are the IFSTS's $\left(X, \tau_{0,1}\right)$ and $\left(X, \tau_{0.2}\right)$

PROOF. Let there exist IFSOS's $A \neq \varnothing_{\sim}$ and $B \neq \underset{\sim}{\varnothing}$ such that $A \cup B=\underset{\sim}{X}, A \cap B=\varnothing_{\sim}$. In this case we obtain

$$
\begin{aligned}
& \underset{\sim}{X}=[] \underset{\sim}{X}=[](A \cup B)=([] A) \cup([] B) \Rightarrow([] A) \cup([] B)=\underset{\sim}{X} ; \\
& \underset{\sim}{\varnothing}=[] \underset{\sim}{\varnothing}=[](A \cap B)=([] A) \cap([] B) \Rightarrow([] A) \cap([] B)=\underset{\sim}{\varnothing},
\end{aligned}
$$

which is a contradiction.

PROPOSITION 3.4. $(\mathrm{X}, \tau)$ is $\mathrm{C}_{5}$-connected iff there exist no nonempty IFSOS's $\mathrm{A}$ and $\mathrm{B}$ in $\mathrm{X}$ such that $\mathrm{A}=\overline{\mathrm{B}}$.

PROOF. ( $\Rightarrow$ :) Suppose that $A$ and $B$ are IFSOS's in $X$ such that $A \neq \underset{\sim}{\varnothing \neq B}$ and $A=\bar{B}$ Since $A=\bar{B}$, $\mathrm{B}$ is an IFSCS, and $\mathrm{A} \neq \underset{\sim}{\varnothing} \Rightarrow \mathrm{B} \neq \underset{\sim}{\mathrm{X}}$. But this is a contradiction to the fact that $\mathrm{X}$ is $\mathrm{C}_{5}$-connected

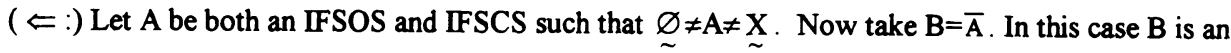
IFSOS and $\mathrm{A} \neq \underset{\sim}{\mathrm{X}} \Rightarrow \mathrm{B}=\overline{\mathrm{A}} \neq \underset{\sim}{\varnothing}$, which is a contradiction.

PROPOSITION 3.5. $(\mathrm{X}, \tau)$ is $\mathrm{C}_{5}$-connected iff there exist no nonempty IFSS's $A$ and $B$ in $X$ such that $B=\bar{A}, B=\overline{c l(A)}, A=\overline{c l(B)}$.

PROOF. $(\Rightarrow$ :) Assume that there exist IFSS's $A$ and $B$ such that $A \neq \varnothing \neq B, B=\bar{A}, B=\overline{\operatorname{cl}(A)}$, $\mathrm{A}=\overline{\mathrm{cl}(\mathrm{B})}$. Since $\overline{\mathrm{cl}(\mathrm{A})}$ and $\overline{\mathrm{cl}(\mathrm{B})}$ are IFSOS's in X, A and B are IFSOS's in X, which is a contradiction ( 


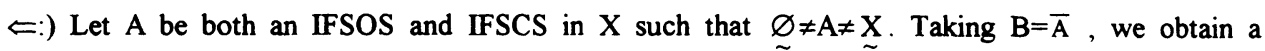
contradiction.

Here we generalize the concepts of $\mathrm{C}_{\mathrm{S}}$-connectedness and $\mathrm{C}_{\mathrm{M}}$-connectedness given by Chaudhuri - Das [10] to the intuitionistic case:

LEMMA 3.1. (a) $\mathrm{A} \cap \mathrm{B}=\underset{\sim}{\varnothing} \Rightarrow \mathrm{A} \subseteq \overline{\mathrm{B}}$, (b) $\mathrm{A} \mp \overline{\mathrm{B}} \Rightarrow \mathrm{A} \cap \mathrm{B} \neq \underset{\sim}{\varnothing}$

DEFINITION 3.2. Let $A$ and $B$ be nonzero IFSS's in $(X, \tau)$. $A$ and $B$ are said to be weakly separated, if $\operatorname{cl}(\mathrm{A}) \subseteq \overline{\mathrm{B}}$ and $\mathrm{cl}(\mathrm{B}) \subseteq \overline{\mathrm{A}}$; and q-separated, if $\operatorname{cl}(\mathrm{A}) \cap \mathrm{B}=\underset{\sim}{\varnothing}=\mathrm{A} \cap \mathrm{cl}(\mathrm{B})$

DEFINITION 3.3. (see Turanli-Çoker [8]) (a) An IFSTS $(X, \tau)$ is said to be $C_{S}$-disconnected, if there exist weakly separated nonzero IFSS's $A$ and $B$ in $(X, \tau)$ such that $\underset{\sim}{X}=A \cup B$

(b) $(\mathrm{X}, \tau)$ is called $\mathrm{C}_{\mathrm{S}}$-connected, if $(\mathrm{X}, \tau)$ is not $\mathrm{C}_{\mathrm{S}}$-disconnected.

(c) $\mathrm{X}$ is said to be $\mathrm{C}_{\mathrm{M}}$-disconnected, if there exist q-separated nonzero IFSS's $A$ and $B$ in $\mathrm{X}$ such that $\underset{\sim}{\mathrm{X}}=\mathrm{A} \cup \mathrm{B}$.

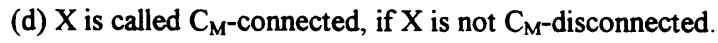

Let us give the connection between these two types of connectedness in IFSTS's:

COROLLARY 3.1. If the IFSTS $X$ is $C_{s}$-connected, then $X$ is also $C_{M}$-connected.

DEFINITION 3.4. (see Turanli-Çoker [8]) An IFSTS $(X, \tau)$ is said to be strongly connected, if there exit no nonempty IFSCS's $A$ and $B$ in $X$ such that $A \cap B=\underset{\sim}{\varnothing}$.

PROPOSITION 3.6. $X$ is strongly connected iff there exist no IFSOS's $A$ and $B$ in $X$ such that $\mathrm{A} \neq \underset{\sim}{\mathrm{X}} \neq \mathrm{B}$ and $\mathrm{A} \cup \mathrm{B}=\underset{\sim}{\mathrm{X}}$.

PROOF. $(\Rightarrow$ :) Let $A$ and $B$ be IFSOS's in $X$ such that $A \neq \underset{\sim}{X \neq B}$ and $A \cup B=\underset{\sim}{X}$. If we take $C=\bar{A}$ and

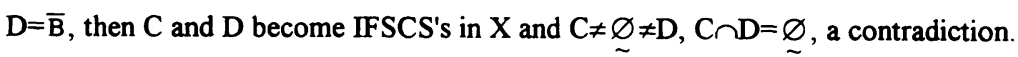

$(\Leftarrow$.$) Use a similar technique as above$

PROPOSITION 3.7. Let $\mathrm{f}:(\mathrm{X}, \tau) \rightarrow(\mathrm{Y}, \psi)$ be a continuous surjection. If $\mathrm{X}$ is strongly connected, then so is $\mathrm{Y}$

PROOF. Suppose that $\mathrm{Y}$ is not strongly connected. In this case there exist IFSCS's $\mathrm{C}$ and $\mathrm{D}$ in $\mathrm{Y}$ such that $C \neq \underset{\sim}{\varnothing} \neq D, C \cap D=\underset{\sim}{\varnothing}$. Since $f$ is continuous, $f^{1}(C)$ and $f^{1}(D)$ are IFSCS's in $X$, and $f^{1}(C) \cap f^{1}(D)=\varnothing_{\sim}, f^{-1}(C) \neq \varnothing_{\sim}, f^{1}(D) \neq \underset{\sim}{\varnothing}$. (If $f^{-1}(C)=\underset{\sim}{\varnothing}$, then $f\left(f^{-1}(C)\right)=C \Rightarrow f(\underset{\sim}{\varnothing})=C \Rightarrow \underset{\sim}{\varnothing}=C, a$ contradiction.) But this is a contradiction, hence $\mathrm{Y}$ is strongly connected, too.

Strong connectedness does not imply $\mathrm{C}_{5}$-connectedness, and the same is true for IFSTS converse, i.e. $C_{5}$ connectedness does not imply strong connectedness. For this purpose see the following counterexamples:

COUNTEREXAMPLES 3.2. Let $X=\{a, b, c, d\}$ (a) If $\tau=\left\{\underset{\sim}{\varnothing} \underset{\sim}{X}, A_{1}, A_{2}, A_{3}, A_{4}\right\}$, where $\left.A_{1}=<x,\{b, c\},\{d\}>, A_{2}=<x,\{d\},\{b, c\}\right\rangle, A_{3}=<x, \varnothing,\{b, c, d\}>, A_{4}=<x,\{b, c, d\}, \varnothing>$, then the IFSTS $(\mathrm{X}, \tau)$ is strongly connected, but not $\mathrm{C}_{5}$-connected. 
(b) If $\tau=\left\{\underset{\sim}{\varnothing}, \underset{\sim}{X}, A_{1}, A_{2}, A_{3}, A_{4}, A_{5}\right\}$, where $A_{1}=<x,\{b, c\},\{d\}>, A_{2}=<x,\{a\},\{c\}>, A_{3}=\langle x,\{a, d\},\{c\}>$, $\left.\mathrm{A}_{4}=<\mathrm{x},\{\mathrm{a}, \mathrm{b}, \mathrm{c}\}, \varnothing>, \mathrm{A}_{5}=<\mathrm{x}, \varnothing,\{\mathrm{c}, \mathrm{d}\}>\right\rangle$, then the IFSTS $(\mathrm{X}, \tau)$ is $\mathrm{C}_{5}$-connected, but not strongly connected

DEFINITION 3.5. (see Turanli-Çoker [8]) (a) If there exists an intuitionistic fuzzy special regular open set $A$ in $X$ such that $\underset{\sim}{\varnothing} \neq \mathrm{A} \neq \underset{\sim}{X}$, then $\mathrm{X}$ is called super disconnected

(b) $\mathrm{X}$ is called super connected, if $\mathrm{X}$ is not super disconnected.

Now we give some characterizations of super connectedness:

PROPOSITION 3.8. The following assertions are equivalent:
(a) $\mathrm{X}$ is super connected.
(b) For each IFSOS $\mathrm{A} \neq \underset{\sim}{\varnothing}$ in $\mathrm{X}$ we have $\mathrm{cl}(\mathrm{A})=\underset{\sim}{\mathrm{X}}$

(c) For each IFSCS $\mathrm{A} \neq \underset{\sim}{\mathrm{X}}$ in $\mathrm{X}$ we have $\operatorname{int}(\mathrm{A})=\underset{\sim}{\varnothing}$

(d) There exist no IFSOS's $A$ and $B$ in such that $A \neq \underset{\sim}{\varnothing} \neq \mathrm{B}, \mathrm{A} \subseteq \overline{\mathrm{B}}$.

(e) There exist no IFSOS's $A$ and $B$ in $X$ such that $A \neq \underset{\sim}{\varnothing \neq B}, B=\overline{\operatorname{cl}(A)}, A=\overline{c l(B)}$

(f) There exist no IFSCS's $A$ and $B$ in $X$ such that $A \neq \underset{\sim}{\varnothing} \neq B, B=\overline{\operatorname{nnt}(A)}, A=\overline{\operatorname{nin}(B)}$

PROOF. (a) $\Rightarrow(\mathrm{b})$ : Assume that there exists an IFSOS $\mathrm{A} \neq \underset{\sim}{\varnothing}$ such that $\mathrm{cl}(\mathrm{A}) \neq \underset{\sim}{\mathrm{X}}$. Now take $\mathrm{B}=\operatorname{int}(\mathrm{cl}(\mathrm{A}))$. Then $\mathrm{B}$ is a proper intuitionistic fuzzy special regular open set in $\mathrm{X}$, and this is in contradiction with the super connectedness of $X$.

(b) $\Rightarrow$ (c) : Let $\mathrm{A} \neq \underset{\sim}{\mathrm{X}}$ be an IFSCS in $\mathrm{X}$. If we take $\mathrm{B}=\overline{\mathrm{A}}$, then $\mathrm{B}$ is an IFSOS in $\mathrm{X}$ and $\mathrm{B} \neq \underset{\sim}{\varnothing}$ Hence $\mathrm{cl}(\mathrm{B})=\underset{\sim}{\mathrm{X}} \Rightarrow \overline{\mathrm{cl}(\mathrm{B})}=\underset{\sim}{\varnothing} \Rightarrow \operatorname{int}(\overline{\mathrm{B}})=\varnothing_{\sim} \Rightarrow \operatorname{int}(\mathrm{A})=\underset{\sim}{\varnothing}$ follows.

(c) $\Rightarrow$ (d) : Let $A$ and $B$ be IFSOS's in $X$ such that $A \neq \underset{\sim}{\varnothing \neq B}$ and $A \subseteq \bar{B}$. Since $\bar{B}$ is an IFCS in $X$ and $\mathrm{B} \neq \underset{\sim}{\varnothing} \Rightarrow \overline{\mathrm{B}} \neq \underset{\sim}{\mathrm{X}}$, we obtain $\operatorname{int}(\overline{\mathrm{B}})=\varnothing_{\sim}$ But, from $\mathrm{A} \subseteq \overline{\mathrm{B}}$, we see that $\underset{\sim}{\varnothing} \mathrm{A}=\operatorname{int}(\mathrm{A}) \subseteq \operatorname{int}(\overline{\mathrm{B}})=\varnothing_{\sim}$, which is a contradiction.

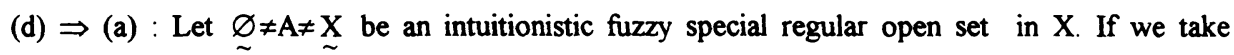
$\mathrm{B}=\overline{\operatorname{cl}(\mathrm{A})}$, we get $\mathrm{B} \neq \underset{\sim}{\varnothing}$. (Because, otherwise we have $\mathrm{B}=\underset{\sim}{\varnothing} \Rightarrow \overline{\operatorname{cl}(\mathrm{A})}=\underset{\sim}{\varnothing} \Rightarrow \operatorname{cl}(\mathrm{A})=\underset{\sim}{\mathrm{X}} \Rightarrow$ $A=\operatorname{int}(\operatorname{cl}(A))=\operatorname{int}(\underset{\sim}{X})=\underset{\sim}{X}$, but the last result contradicts the fact $A \neq \underset{\sim}{X}$.$) We also have A \subseteq \bar{B}$, and this is a contradiction, too.

(a) $\Rightarrow$ (e) : Let $A$ and $B$ be IFSOS's in $X$ such that $A \neq \underset{\sim}{\varnothing \neq B}$ and $B=\overline{\operatorname{cl}(A)}, A=\overline{\operatorname{cl}(B)}$ Now we have $\operatorname{int}(\operatorname{cl}(A))=\operatorname{int}(\bar{B})=\overline{\operatorname{cl}(B)}=A$ and $A \neq \underset{\sim}{\varnothing}, A \neq \underset{\sim}{X}$. (If not, i.e. if $A=\underset{\sim}{X}$, then $\underset{\sim}{X}=\overline{\operatorname{cl}(B)} \Rightarrow \underset{\sim}{\varnothing}=\operatorname{cl}(B) \Rightarrow$ $\mathrm{B}=\varnothing_{\sim}$.) But this is a contradiction

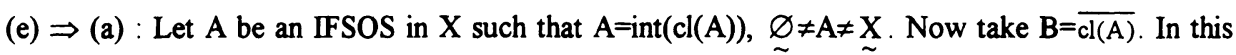
case we get $\mathrm{B} \neq \varnothing$ and $\mathrm{B}$ is an IFSOS in $\mathrm{X}$ and $\mathrm{B}=\overline{\operatorname{cl}(\mathrm{A})}$ and $\overline{\operatorname{cl}(\mathrm{B})}=\overline{\operatorname{cl}(\overline{\operatorname{cl}(\mathrm{A}))}}=\overline{\overline{\operatorname{in}(\operatorname{cl}(\mathrm{A}))}}=\operatorname{int}(\mathrm{cl}(\mathrm{A}))=\mathrm{A}$. which is a contradiction. 
(e) $\Rightarrow$ (f) : Let $A$ and $B$ IFSCS's in $X$ such that $A \neq \underset{\sim}{X} \neq B, B=\overline{\operatorname{int}(A)}, A=\overline{\operatorname{int}(B)}$ Taking $C=\bar{A}$ and

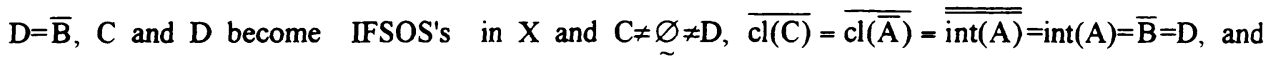
similarly $\overline{\operatorname{cl}(\mathrm{D})}=\mathrm{C}$. But this is an obvious contradiction.

$(\mathrm{f}) \Rightarrow(\mathrm{e})$ : One can use a similar technique as in (e) $\Rightarrow(\mathrm{f})$.

PROPOSITION 3.9. Super connectedness implies $\mathrm{C}_{5}$-connectedness.

PROOF. Obvious.

But the reverse implication to Proposition 3.9 does not hold in general

COUNTEREXAMPLE 3.3. Let $X=\{a, b, c, d\}$ and the IFST $\tau=\left\{\underset{\sim}{\varnothing} \underset{\sim}{X}, A_{1}, A_{2}, A_{3}, A_{4}\right\}$ on $X$, where $A_{1}=<x,\{a\},\{c, d\}>, A_{2}=<x,\{d\},\{a, c\}>, A_{3}=<x,\{a, d\},\{c\}>, A_{4}=<x, \varnothing,\{a, c, d\}>$. Then the IFSTS $(\mathrm{X}, \tau)$ is $\mathrm{C}_{5}$-connected, but not super connected

PROPOSITION 3.10. Let $\mathrm{f}:(\mathrm{X}, \tau) \rightarrow(\mathrm{Y}, \psi)$ be a continuous surjection. If $\mathrm{X}$ is super connected, then so is $\mathrm{Y}$.

PROOF. Suppose that $\mathrm{Y}$ is super disconnected. In this case there exist IFSOS's $\mathrm{C}$ and D in $\mathrm{Y}$ such that $C \neq \underset{\sim}{\varnothing} \neq D, C \subseteq \bar{D}$ Since $f$ is continuous, $f^{1}(C)$ and $f^{1}(D)$ are IFSOS's in $X$, and

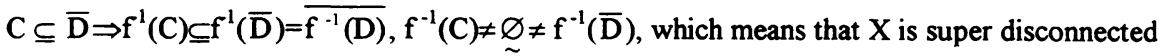

Now we shall summarize the interrelations between several types of connectedness in IFSTS's.

$\begin{array}{cc}\text { super connectedness } & \mathrm{C}_{\mathrm{S}} \text {-connectedness } \\ \downarrow & \downarrow \\ \mathrm{C}_{5} \text {-connectedness } & \mathrm{C}_{\mathrm{M}} \text {-connectedness } \\ \downarrow & \\ \text { connectedness } & \end{array}$

Here we generalize the idea of fuzzy $\mathrm{C}_{\mathrm{i}}$-connectedness in fuzzy topological spaces and in intuitionistic fuzzy topological spaces (see Ajmal-Kohli [11], Chaudhuri-Das [10] and Turanli-Çoker [8] to the intuitionistic case:

DEFINITION 3.6. Let $N$ be an IFSS in $(X, \tau)$

(a) If there exist IFSOS's $\mathrm{M}$ and $\mathrm{W}$ in $\mathrm{X}$ satisfying the following properties, then $\mathrm{N}$ is called $\mathrm{C}_{1}$ disconnected $(\mathrm{i}=1,2,3,4)$ :

$C_{1}: N \subseteq M \cup W, M \cap W \subseteq \bar{N}, N \cap M \neq \varnothing_{\sim}, N \cap W \neq \varnothing_{\sim}, \quad C_{2}: N \subseteq M \cup W, N \cap M \cap W=\varnothing_{\sim}, N \cap M \neq \underset{\sim}{\varnothing}, N \cap W \neq \underset{\sim}{\varnothing}$, $\mathrm{C}_{3}: \mathrm{N} \subseteq \mathrm{M} \cup \mathrm{W}, \mathrm{M} \cap \mathrm{W} \subseteq \overline{\mathrm{N}}, \mathrm{M} \nsubseteq \overline{\mathrm{N}}, \mathrm{W} \nsubseteq \overline{\mathrm{N}}, \quad \mathrm{C}_{4}: \mathrm{N} \subseteq \mathrm{M} \cup \mathrm{W}, \mathrm{N} \cap \mathrm{M} \cap \mathrm{W}=\varnothing_{\sim}, \mathrm{M} \nsubseteq \overline{\mathrm{N}}, \mathrm{W} \nsubseteq \overline{\mathrm{N}}$.

(b) $\mathrm{N}$ is said to be $\mathrm{C}_{1}$-connected ( $\left.\mathrm{i}=1,2,3,4\right)$, if $\mathrm{N}$ is not $\mathrm{C}_{1}$-disconnected $(\mathrm{i}=1,2,3,4)$

Obviously, one can obtain the following implications between several types of $C_{1}$-connectedness $(\mathrm{i}=1,2,3,4)$ :

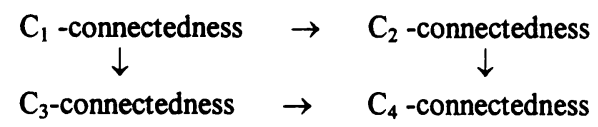

None of these implications are reversible, as the following counterexamples state: 
COUNTEREXAMPLES 3.4. Consider the IFST $\tau$ on $X=\{a, b\}$, where $\left.\tau=\left\{\underset{\sim}{\varnothing} \underset{\sim}{\mathrm{X}}, \mathrm{A}_{1}, \mathrm{~A}_{2}, \mathrm{~A}_{3}, \mathrm{~A}_{4}, \mathrm{~A}_{5}, \mathrm{~A}_{6}, \mathrm{~A}_{7}\right\}, \mathrm{A}_{1}=<\mathrm{x},\{\mathrm{a}\}, \varnothing\right\}>, \mathrm{A}_{2}=<\mathrm{x},\{\mathrm{b}\}, \varnothing>, \mathrm{A}_{3}=<\mathrm{x}, \varnothing,\{\mathrm{a}\}>, \mathrm{A}_{4}=<\mathrm{x}, \varnothing,\{\mathrm{b}\}>$, $A_{5}=<x,\{a\},\{b\}>, A_{6}=<x,\{b\},\{a\}>, A_{7}=<x, \varnothing, \varnothing>$ and take the IFSS $N=<x, \varnothing,\{a\}>$ in $X$.

(a) $\mathrm{N}$ is $\mathrm{C}_{2}$-connected, but not $\mathrm{C}_{1}$-connected. [Namely, $\mathrm{A}_{2}$ and $\mathrm{A}_{3}$ do satisfy the properties in $\left(C_{1}\right)$ ]

(b) $\mathrm{N}$ is $\mathrm{C}_{3}$-connected, but not $\mathrm{C}_{1}$-connected

COUNTEREXAMPLE 3.5. Consider the IFST $\tau$ on $X=\{a, b, c, d\}$, where $\tau=\left\{\underset{\sim}{\varnothing} \underset{\sim}{X}, A_{1}, A_{2}, A_{3}, A_{4}\right\}$, $\left.A_{1}=<x,\{a\},\{b, c\}>, \quad A_{2}=<x,\{b, c\},\{a\}>, \quad A_{3}=<x, \varnothing,\{a, b, c\}\right\rangle, \quad A_{4}=<x,\{a, b, c\}, \varnothing>$ The IFSS $\mathrm{N}=<\mathrm{x},\{\mathrm{a}\},\{\mathrm{b}\}>$ in $\mathrm{X}$ is $\mathrm{C}_{4}$-connected, but not $\mathrm{C}_{3}$-connected [Namely, $\mathrm{A}_{1}$ and $\mathrm{A}_{2}$ do satisfy the properties in $\left(\mathrm{C}_{3}\right)$.]

COUNTEREXAMPLE 3.6. Consider the IFST $\tau$ on $X=\{a, b, c\}$, where $\tau=\left\{\underset{\sim}{\varnothing} \underset{\sim}{X}, A_{1}, A_{2}, A_{3}\right\}, A_{1}=<x, \varnothing,\{a\}>, A_{2}=<x,\{a\},\{b, c\}>, A_{3}=<x,\{a\}, \varnothing>$. The IFSS $N=<x,\{a\}, \varnothing>$ in $X$ is $C_{4}$-connected, but not $C_{2}$-connected. [Namely, $A_{1}$ and $A_{2}$ do satisfy the properties in $\left(C_{2}\right)$.]

\section{REFERENCES}

[1] ZADEH, L.A., Fuzzy sets, Information and Control 8 (1965) 338-353.

[2] ATANASSOV, K., Intuitionistic fuzzy sets, in: V. Sgurev, Ed., VII ITKR's Session, Sofia, June 1983 (Central Sci. and Techn. Library, Bulg. Academy of Sciences, 1984)

[3] ATANASSOV, K., Intuitionistic fuzzy sets, Fuzzy Sets and Systems 20 (1986) 87-96.

[4] COKER, D., A note on intuitionistic sets and intuitionistic points, to appear in Doga TU. J. Math.

[5] ÇOKER, D., An introduction to intuitionistic fuzzy topological spaces, to appear in Fuzzy Sets and Systems.

[6] ÇOKER, D. and ES, A.H., On fuzzy compactness in intuitionistic fuzzy topological spaces, Journal of Fuzzy MathematIFSCS 3-4 (1995) 899-909.

[7] COSKUN, E. and ÇOKER, D., On neighborhood structures in intuitionistic topological spaces, submitted to Mathematica Balkanica.

[8] TURANLI and ÇOKER, D., On fuzzy connectedness in intuitionistic topological spaces, submitted to Information Sciences.

[9] ÇOKER, D., An introduction to intuitionistic topological spaces, submitted to Doga TU.J.Math..

[10] CHAUDHURI, A.K. and DAS, P., Fuzzy connected sets in fuzzy topological spaces, Fuzzy Sets and Systems 49(1992) 223-229.

[11] AJMAL, N. and KOHLI, J.K., Connectedness in fuzzy topological spaces, Fuzzy Sets and Systems 31 (1989) 369-388. 


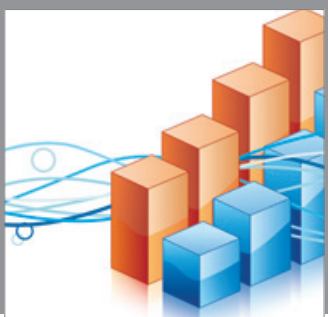

Advances in

Operations Research

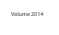

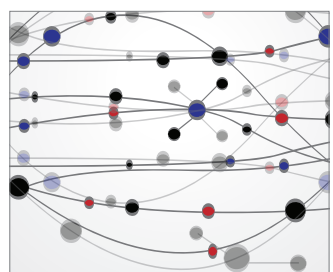

\section{The Scientific} World Journal
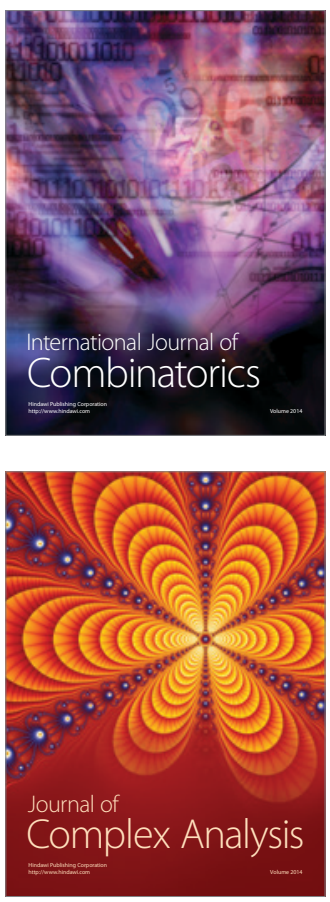

International Journal of

Mathematics and

Mathematical

Sciences
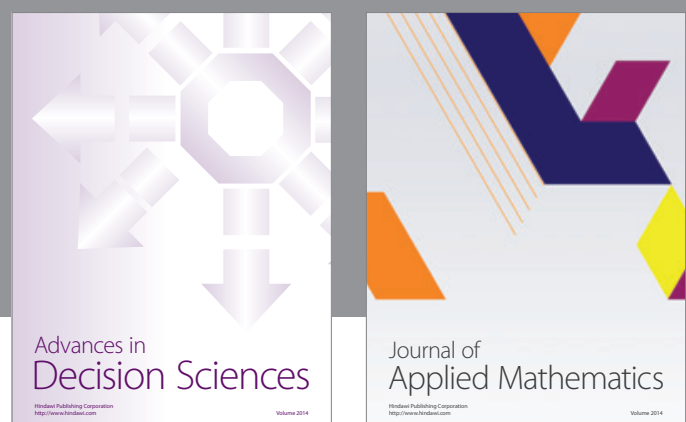

Journal of

Applied Mathematics
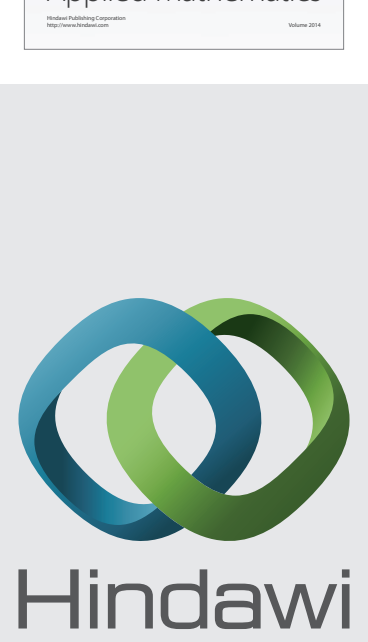

Submit your manuscripts at http://www.hindawi.com
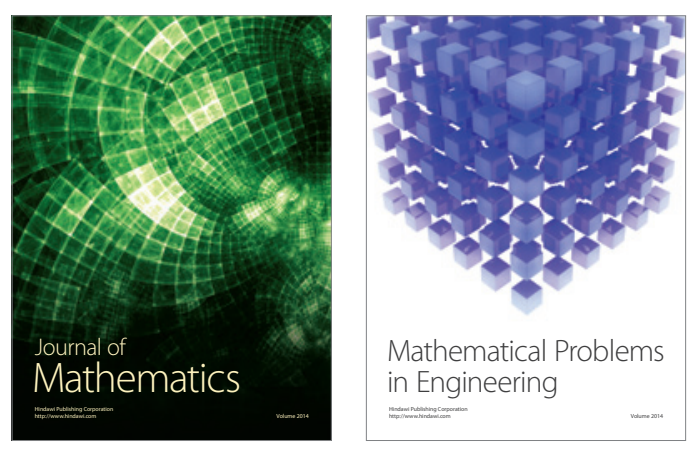

Mathematical Problems in Engineering
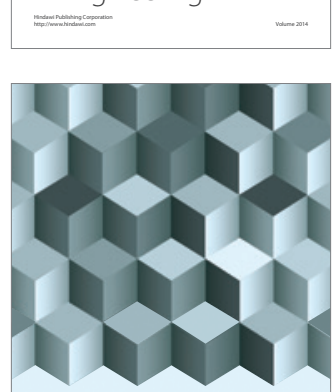

Journal of

Function Spaces
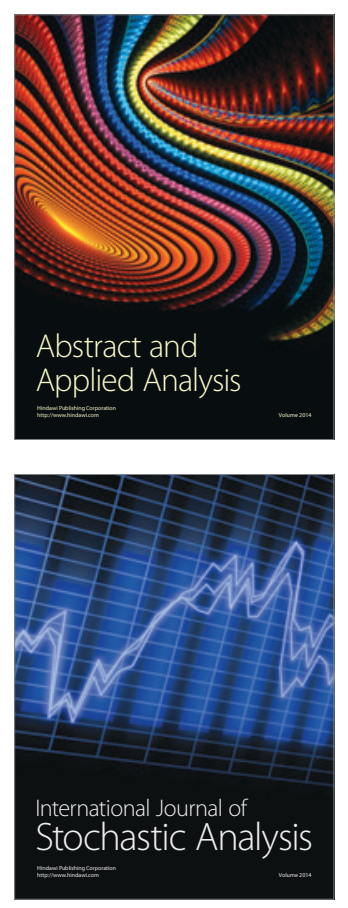

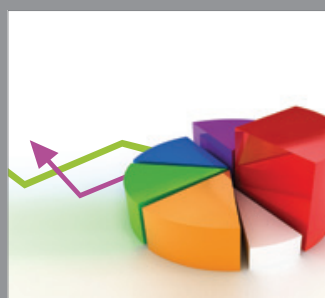

ournal of

Probability and Statistics

Promensencen
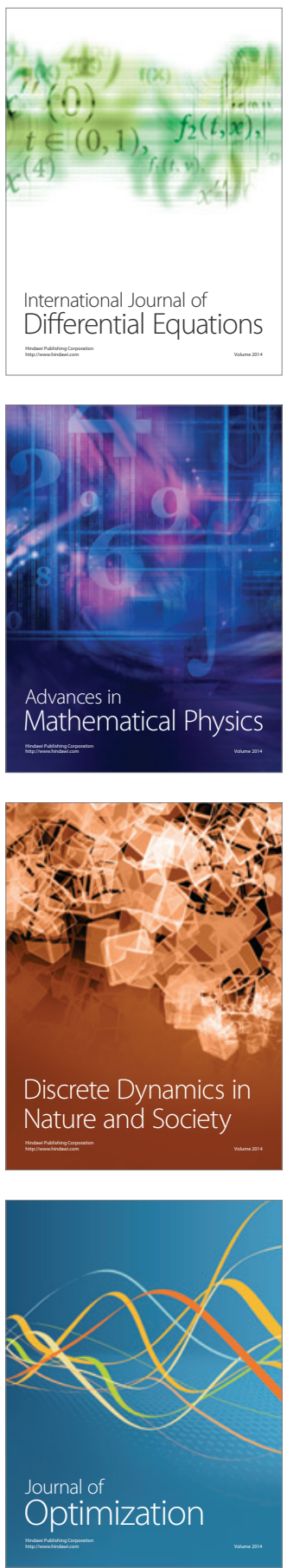